\title{
A historical legacy of antibiotic utilization on bacterial seed banks in sediments
}

Laura Madueño ${ }^{1}$, Christophe Paul ${ }^{1}$, Thomas Junier ${ }^{2}$, Zhanna Bayrychenko ${ }^{1}$, Sevasti Filippidou ${ }^{1}$, Karin Beck $^{3}$, Gilbert Greub ${ }^{4}$, Helmut Bürgmann ${ }^{3}$, Pilar Junier ${ }^{\text {Corresp. } 1}$

1 Laboratory of Microbiology, Institute of Biology, University of Neuchatel, Neuchâtel, NE, Switzerland

2 Vital-IT group, Swiss Institute of Bioinformatics, Lausanne, Switzerland

3 Surface Waters - Research and Management, Swiss Federal Institute of Technology, Zurich, Kastanienbaum, Switzerland

4 Institute of Microbiology, University Hospital of the University of Lausanne, Lausanne, Switzerland

Corresponding Author: Pilar Junier

Email address: pilar.junier@unine.ch

The introduction of antibiotics for both medical and non-medical purposes has had a positive effect on human welfare and agricultural output in the past century. However, there is also an important ecological legacy regarding the use of antibiotics and the consequences of increased levels of these compounds in the environment as a consequence of their use and disposal. This legacy was investigated by quantifying two antibiotic resistance genes (ARG) conferring resistance to tetracycline (tet(W)) and sulfonamide (su/1) in bacterial seed bank DNA in sediments. The industrial introduction of antibiotics caused an abrupt increase in the total abundance of tet(W) and a steady increase in sull. The abrupt change in tet(W) corresponded to an increase in relative abundance from ca. 1960 that peaked around 1976. This pattern of accumulation was highly correlated with the abundance of specific members of the seed bank community belonging to the phylum Firmicutes. In contrast, the relative abundance of sul1 increased after 1976. This correlated with a taxonomically broad spectrum of bacteria, reflecting sul1 dissemination through horizontal gene transfer. The accumulation patterns of both ARGs correspond broadly to the temporal scale of medical antibiotic use. Our results show that the bacterial seed bank can be used to look back at the historical usage of antibiotics and resistance prevalence. 


\section{A historical legacy of antibiotic utilization on bacterial seed banks in sediments}

\section{Short title: Antibacterial legacy in seed banks}

3

4 Laura Madueño ${ }^{1 *}$, Christophe Paul ${ }^{1 *}$, Thomas Junier ${ }^{1,2^{*}}$, Zhanna Bayrychenko ${ }^{1}$, Sevasti

5 Filippidou ${ }^{1}$, Karin Beck ${ }^{3}$, Gilbert Greub ${ }^{4}$, Helmut Bürgmann ${ }^{3}$ and Pilar Junier ${ }^{1 \&}$

$6{ }^{1}$ Laboratory of Microbiology, Institute of Biology, University of Neuchâtel. Rue Emile-Argand

7 11, CH-2000, Neuchâtel, Switzerland

8 2Vital-IT group, Swiss Institute of Bioinformatics, CH-1015, Lausanne, Switzerland

$9{ }^{3}$ Eawag, Swiss Federal Institute of Aquatic Science and Technology, CH-6047 Kastanienbaum, 10 Switzerland

$11{ }^{4}$ Institute of Microbiology, University of Lausanne and University Hospital (CHUV); CH-1011, 12 Lausanne, Switzerland

13

$14{ }^{*}$ These authors contributed equally to this work.

15 \& corresponding author: pilar.junier@unine.ch

\section{Abstract}

18 The introduction of antibiotics for both medical and non-medical purposes has had a positive 19 effect on human welfare and agricultural output in the past century. However, there is also an 20 important ecological legacy regarding the use of antibiotics and the consequences of increased 21 levels of these compounds in the environment as a consequence of their use and disposal. This 22 legacy was investigated by quantifying two antibiotic resistance genes (ARG) conferring 23 resistance to tetracycline $(\operatorname{tet}(\mathrm{W}))$ and sulfonamide $(s u l 1)$ in bacterial seed bank DNA in 
24 sediments. The industrial introduction of antibiotics caused an abrupt increase in the total

25 abundance of tet $(\mathrm{W})$ and a steady increase in sul1. The abrupt change in $\operatorname{tet}(\mathrm{W})$ corresponded to

26 an increase in relative abundance from ca. 1960 that peaked around 1976. This pattern of

27 accumulation was highly correlated with the abundance of specific members of the seed bank

28 community belonging to the phylum Firmicutes. In contrast, the relative abundance of sul1

29 increased after 1976. This correlated with a taxonomically broad spectrum of bacteria, reflecting

30 sul1 dissemination through horizontal gene transfer. The accumulation patterns of both ARGs

31 correspond broadly to the temporal scale of medical antibiotic use. Our results show that the

32 bacterial seed bank can be used to look back at the historical usage of antibiotics and resistance

33 prevalence.

35 Introduction

36 The use of antibiotics to treat infectious diseases represents one of the major scientific 37 achievements of the $20^{\text {th }}$ century. Millions of lives have been saved since the introduction of 38 antibiotics into general medical practice for the treatment of a large range of bacterial infections, 39 as well as other medical procedures (Marti et al. 2014). After the initial use of antibiotics in medicine, the utilization of antibiotics to increase agricultural productivity has become a common practice (Carlet et al. 2011). Although the positive effect of the so-called antibiotic era on human welfare is not disputed, increased awareness of the risks posed by poor antibiotic stewardship counterbalances this success. Nowadays it is becoming clear that the disposal of

44 antibiotics in natural ecosystems can have far-reaching consequences (Baquero et al. 2008). 45 Recent studies on antibiotics and the emergence of resistance suggest that the function of 46 antibiotics in nature cannot be explained solely within the paradigm of chemical weapons in 
47 which these compounds have been used since their industrialized production (Aminov 2009;

48 Aminov 2010). Instead, antibiotics and determinants of resistance have been proposed to be a

49 fundamental component of the ecology and evolution of microbial ecosystems. Most of the

50 antibiotics used today are chemical derivatives of small bioactive molecules that might perform a

51 multitude of functions (Taylor et al. 2011). In nature these molecules are thought to be produced

52 at very low concentrations (Martinez 2008), and for example, a study conducted at sub-inhibitory

53 concentrations with erythromycin and rifampicin has shown that this low concentrations of

54 antibiotics can modulate not only growth but also bacterial metabolism (Goh et al. 2002).

55 Therefore, antibiotics can be expected to modulate microbial interactions and regulate the

56 dynamics of microbial communities (Martinez 2008).

57 Although antibiotic resistance could potentially emerge anywhere and at any given time, the 58 emergence of a resistance factor has been generally associated with some fitness cost, and 59 therefore novel resistance genes are expected to be under strong negative selection pressure 60 (Bengtsson-Palme et al. 2017). In this context, the industrialized production, use, and disposal of 61 antibiotics is a relatively recent phenomenon that has presumably exerted a positive selective 62 pressure for pathogens to develop antibiotic resistance either as a consequence of mutation or by 63 horizontally acquiring naturally occurring antibiotic resistance systems (Blair et al. 2015; Taylor 64 et al. 2011). The increasing levels of antibiotic resistance in bacteria isolated from clinical samples is a problem that threatens health care systems worldwide (Wright 2010). Therefore, understanding the effect of antibiotic use on the natural reservoirs of ARGs and analyzing this

67 recent historical event (the antibiotic era) in terms of the levels of circulating antibiotic resistance 68 genes (ARGs) are essential to develop a management strategy to reduce current and future risks. 
69 ARGs were clearly present in microbial communities before the antibiotic era as shown by

70 phylogenetic analysis of genes conferring resistance to different classes of antibiotics (Aminov \&

71 Mackie 2007). Evidence from work conducted on ancient DNA in permafrost (D'Costa et al.

72 2011) and an isolated cave (Bhullar et al. 2012) also support the existence of resistance without

73 human intervention. Given the presumed role of human activity in the levels of resistance in the

74 environment, one can thus expect an increasing abundance of such genes in the past century.

75 However, direct evidence for this is currently restricted to a limited number of studies. For

76 example, soil archives from two regions in Europe clearly demonstrate a link between the history

77 of antibiotic use and the increase in the abundance of various genes conferring resistance to a

78 large range of antibiotics (Graham et al. 2016; Knapp et al. 2010). Furthermore, the analysis of

79 soil records also demonstrated the interconnection between the medical and non-medical use of

80 antibiotics, as well as the effect of changes in policy towards a more strict stewardship in the

81 reduction of ARGs from natural pools (Graham et al. 2016).

82 Besides soils, aquatic ecosystems have been identified as a key ecological component driving the

83 emergence, spread, and persistence of antibiotic resistance (Baquero et al. 2008; Taylor et al.

84 2011). Water constitutes a circulating path of antibiotic-resistant organisms from human and

85 animal populations to the environment and back into these populations, via the connection

86 between wastewater treatment and drinking water production, respectively (Baquero et al. 2008).

87 Lake sediments are a major concern because they are a main environmental end-point not only

88 for bacteria, but also for ARGs and antimicrobial agents (Kümmerer 2009). The high numbers of

89 cells in sediments make resuspended sediment material a potential source of resistance

90 determinants. At the same time, lake sediments are natural environmental archives. Thus, the

91 study of the sedimentary record might provide insights into the historical legacy of the antibiotic 
92 era and the accumulation of ARG in the environment. Attempts to use DNA extracted from

93 sediments to investigate antibiotic resistance in aquatic systems have been made (Thevenon et al.

94 2012), but suffer from uncertainty regarding the preservation of the environmental signal in the

95 sediments. Sediment microbial communities are strongly shaped by the redox gradients

96 experienced during early diagenesis, and it is therefore unclear how much of the originally

97 resistant community, or of their resistance determinants, is preserved in deeper sediment layers,

98 and how this relationship is affected by environmental factors. The use of microbial seed banks

99 preserved in the sedimentary record as a proxy offers a likely solution to these problems.

100 The seed bank can be broadly defined as a reservoir of dormant cells that can potentially be

101 resuscitated under favorable environmental conditions (Lennon \& Jones 2011). One of the

102 defining features of dormant cells is their reduced metabolic activity (Driks 2002), decreasing the

103 uncertainty generated by environmental changes during sediment diagenesis (Vuillemin et al

104 2016). In addition, dormant cells are more resistant to degradation than their actively growing

105 counterparts (Abecasis et al. 2013). We have used the latter property to develop a specific

106 extraction method to enrich DNA from spores as an example of dormant cell forms (Wunderlin

107 et al. 2016; Wunderlin et al. 2014b). With this approach we have previously shown that one

108 particular group of bacteria capable of dormancy (endospore-forming Firmicutes) can be used as

109 paleoecological biomarkers of the impact of lake eutrophication on microbial communities in

110 sediments (Wunderlin et al. 2014a). Using the same selective method we investigated if the

111 historical antibiotic usage has affected the levels of ARG found in the natural seed bank bacterial

112 community. The hypothesis in this case is that information regarding the abundance and

113 frequency of ARGs as the consequence of antibiotic use will be reflected in the dormant cells

114 deposited in the sediment, regardless of the presence of the antibiotics themselves or intrinsic 
115 selection by the environment. To test this hypothesis, we investigated the levels of two ARGs

116 conferring resistance to two antibiotics that were introduced earlier in the antibiotic era and with

117 diverging histories of use. The gene $\operatorname{tet}(\mathrm{W})$ is one of the genes conferring resistance to

118 tetracycline, a class of broad-spectrum antibiotics isolated from Streptomyces spp. between 1947

119 and 1950, constituting one of the earliest classes of antibiotics described and used (Roberts \&

120 Schwarz 2016). The second ARG studied here, sul1, is one of the genes conferring resistance to

121 sulfonamide drugs, which were also among the earliest antibiotics discovered. However, in

122 contrast to tetracycline, sulfonamide and its derivatives were obtained by systematic screening of

123 chemically synthesized compounds (Aminov 2010; Davies \& Davies 2010). The diverging

124 histories of production and use of these two antibiotics, as well as, the differences in the

125 mechanisms generating resistance, will allow to proof the concept of using the seed bank to

126 investigate the legacy of human antibiotics history, as well as to develop a method to investigate

127 the natural history of antibiotics in the environment.

128

\section{Material and Methods}

\section{Site description and sampling}

131 A sediment core was retrieved with a gravity corer (UWITEC, Mondstein, Au) in August 2011

132 in an inactive canyon (C1) on the eastern side of the Rhone delta in Lake Geneva (Switzerland)

133 (CAN01, coordinates 559901-139859, $79 \mathrm{~m}$ depth, $105 \mathrm{~cm}$ ). This core has previously been dated

134 by creating an age model based on ${ }^{137} \mathrm{Cs}$ (corresponding to the 1963-1964 atmospheric nuclear

135 tests maximum fallout and the 1986 Chernobyl accident) and magnetic susceptibility, which

136 allowed assigning years to the sediment depth (Wunderlin et al. 2014a). Additional

137 environmental data was obtained from a second sediment core (CAN02, 559405-140504, $96 \mathrm{~m}$ 
138 depth, $107 \mathrm{~cm}$ ) retrieved in parallel to the sediment used for biological analysis. This second core

139 was split in two lengthwise halves for a sedimentological description and chemical analysis.

140 Manganese and iron measurements were performed at the University of Barcelona by X-ray

141 fluorescence using an AVAATECH XRF core scanner (2000 A, 10kV and 30kV) every $2 \mathrm{~mm}$.

142 Correlation between the two sediment cores was carried out by visual description, sediment color

143 and texture and by comparing magnetic susceptibility (MS) and density core profiles in order to

144 assign the manganese and iron profiles to the ages investigated with CAN01 (Wunderlin et al.

145 2014a).

\section{DNA extraction}

147 Total community DNA and DNA from the seed bank were obtained using an indirect extraction

148 method. The extraction of cells from sediments was performed as previously described

149 (Wunderlin et al. 2013). The cells extracted from $3 \mathrm{~g}$ of wet sediment were filtered onto two

150 different 0.2 um pore-size nitrocellulose filters (Merck Millipore, Darmstadt, Germany). In one

151 of the filters (1.5 grams of sediment) a treatment to separate seed bank from vegetative cells was

152 performed on the biomass collected on nitrocellulose filters, as previously described (Wunderlin

153 et al. 2016; Wunderlin et al. 2014b). The first step consisted of the lysis of vegetative cells by

154 heat, enzymatic agents (lysozyme) and chemicals (Tris-EDTA, NaOH, SDS). Further DNase

155 digestion was used to destroy any traces of free DNA. DNA was then extracted from the pre-

156 treated (seed bank DNA) and the second non-pre-treated filter (total community DNA) using a

157 modified protocol with the FastDNA®SPIN kit for soil (MP Biomedicals, USA) (Wunderlin et

158 al. 2013), in which the lysing matrix was submitted to two successive bead-beating steps.

159 Supernatants from each bead-beating step were treated separately downstream according to

160 manufacturer's instructions. The two DNA extracts per filter were pooled by precipitation with 
$1610.3 \mathrm{M} \mathrm{Na}$-acetate and ethanol $(99 \%)$, stored at $-20^{\circ} \mathrm{C}$ overnight and centrifuged for $1 \mathrm{~h}$ at 21.460

$162 \mathrm{xg}$ and $4^{\circ} \mathrm{C}$. Supernatant was removed and the pellet was washed with 1 volume of $70 \%$ ethanol

163 and centrifuged for $30 \mathrm{~min}$ at $21.460 \mathrm{x} \mathrm{g}$ and $4^{\circ} \mathrm{C}$. Supernatant was removed and the residual

164 ethanol was allowed to evaporate at room temperature. DNA was re-suspended in $50 \mu 1$ of PCR-

165 grade water. DNA was quantified using Qubit ${ }^{2}$ dsDNA HS Assay Kit on a Qubit ${ }^{2} .0$

166 Fluorometer (Invitrogen, Carlsbad, CA, USA). DNA yield varied from 1.6 to $16 \mu \mathrm{g}$ DNA/g for

167 the total community DNA, and 6-23 ng DNA/g sediment for the seed bank DNA.

168 Quantitative PCR on $\operatorname{tet}(\mathrm{W})$ and $\operatorname{sul} 1$ genes

169 Quantitative Taqman ${ }^{\circledR}-\mathrm{PCR}$ on sull and tet(W) genes was performed in 384-well plates using a

170 LightCycler ${ }^{\circledR} 480$ Instrument II (Roche, Switzerland). For sul1, the primers used were qSUL653f

171 and qSUL719r with tpSUL1 probe (Heuer \& Smalla 2007). The reaction mix for sul1 consisted

172 of $2 \mu \mathrm{L}$ of DNA template (between 0.08 and $1.39 \mathrm{ng} / \mu \mathrm{L}$ for seed bank DNA and $10 \mathrm{ng} / \mu \mathrm{L}$ for

173 total community DNA), $0.025 \mu \mathrm{M}$ of each primer, $0.25 \mu \mathrm{M}$ of TaqMan probe and $1 \mathrm{x}$

174 TaqMan®Fast Universal PCR Master Mix (Applied Biosystems, USA). Total reaction volume of

$17510 \mu \mathrm{L}$ was reached with PCR-grade water. For tet $(\mathrm{W})$, the primers used were tetW-F and tetW-R

176 with tetW-S probe (Walsh et al. 2011). The reaction mix for tet(W) consisted of $2 \mu \mathrm{L}$ of DNA

177 template (between 0.08 and $1.39 \mathrm{ng} / \mu \mathrm{L}$ for seed bank DNA and $15 \mathrm{ng} / \mu \mathrm{L}$ for total community 178 DNA), $0.025 \mu \mathrm{M}$ of each primer, $0.1 \mu \mathrm{M}$ of TaqMan probe and $1 \mathrm{x}$ TaqMan ${ }^{\circledR} F$ ast Universal 179 PCR Master Mix (Applied Biosystems, USA). Total reaction volume of $10 \mu \mathrm{L}$ was reached with 180 PCR-grade water. The qPCR program was the same for both genes and started with a hold at $18195^{\circ} \mathrm{C}$ for $10 \mathrm{~min}$, followed by 45 cycles of denaturation at $95^{\circ} \mathrm{C}$ for $15 \mathrm{~s}$ and 182 annealing/elongation at $60^{\circ} \mathrm{C}$ for $1 \mathrm{~min}$. The qPCR assays were performed in technical triplicates 183 on samples, standards and negative controls. The negative controls consisted of PCR blanks with 
184 only the reaction mix and of PCR blanks containing the mix and $2 \mu \mathrm{L}$ of PCR-grade water.

185 Standard curves were prepared from serial 10-fold dilutions of plasmid DNA containing the

186 respective target gene in a range of $5 \times 10^{7}$ to 50 gene copies. For sul1, control plasmids and

187 standard curves were prepared as previously described (Heuer \& Smalla 2007). For tet(W),

188 standard curves were prepared as previously described (Walsh et al. 2011). The effect of

189 inhibitors on amplification was tested for all the samples and for both genes. All samples were

190 spiked with $10^{4}$ copies of plasmid DNA containing the tet(W) or the sul1 gene and amplified

191 together with the same set of non-spiked samples and control DNA and the results indicated that

192 inhibition was negligible.

\section{Sequencing and data analysis}

194 Purified DNA extracts were sent to Fasteris (Geneva, Switzerland) for 16S rRNA amplicon 195 sequencing using Illumina MiSeq platform (Illumina, San Diego, USA), generating 250 bp 196 paired-end reads. The hypervariable V3-V4 region was targeted using universal primers 197 Bakt_341F (5'-CCTACGGGNGGCWGCAG-3') and Bakt_805R (5'198 GACTACHVGGGTATCTAATCC-3') (Herlemann et al. 2011). Analysis of the dataset was 199 made using Mothur (Schloss et al. 2009) following the standard MiSeq SOP(Kozich et al. 2013).

200 The SILVA NR v123 reference database (Quast et al. 2013) was used for the alignment of 201 amplicons and the taxonomic assignment of representative OTUs. After quality filtering and 202 removal of chimeras, a total of 2'837'393 amplicons was obtained (625'339 unique sequences). 203 Singletons were removed prior to the clustering into OTUs. The number of singletons in the 204 dataset was 560'158. Clustering of the 2’277'235 remaining sequences (65'181 unique 205 sequences) was made using a threshold of 97\% identity. Finally, 11'802 OTUs constitute the 
206 dataset. The generated datasets were submitted to NCBI under the Bioproject accession number

207 PRJNA396276.

208 Statistical and multivariate analyses

209 Community and statistical analyses were performed using R version 3.4.0 (Team 2014) and the 210 phyloseq and vegan packages (McMurdie \& Holmes 2013; Oksanen et al. 2017). Pairwise 211 correlations between OTU relative abundances and ARGs frequency were calculated using 212 Spearman's rank correlation coefficient. The same analysis was performed using the 213 iron/manganese ratio as a proxy to lake eutrophication. Seed bank community was analyzed by 214 principal coordinates analysis (PCoA), based on Bray-Curtis dissimilarity and Hellinger 215 transformation of the OTUs table (community matrix). Environmental parameters and ARGs 216 abundance/frequency were standardized and passively fitted to the ordination. Only significant 217 parameters were displayed $(\mathrm{p}<0.05)$.

219 Results

220 Quantification of ARGs in seed bank communities from sediment samples

221 Seed bank DNA was extracted from a sediment core previously validated for paleoecology

222 covering approximately the last hundred years of sediment accumulation in Lake Geneva 223 (Wunderlin et al. 2014a). ARG in seed bank DNA was measured by quantifying the number of 224 copies of genes conferring resistance to tetracycline (tet $(\mathrm{W})$ gene) and sulfonamide (sul1 gene), 225 two commonly reported antibiotics detected in environmental settings (Davies \& Davies 2010).

226 ARG quantification was standardized to DNA yield instead of number of 16S rRNA gene copies 227 given the changes in community composition over time (see next section), and the variable 228 number of copies of this molecular marker in different taxonomic groups (Lee et al. 2009). The 
229 detection of ARGs in the seed bank DNA changed beginning in $1960(\operatorname{tet}(\mathrm{W}))$ and $1970($ sul1).

230 However, the accumulation pattern was different for the two ARGs. In the case of tet(W), the 231 total abundance of the gene (copies/g of sediment) increased by an order of magnitude since 2321965 compared to the values obtained from 1920 to 1960 (Supplementary Figure 1). Moreover, 233 the relative abundance of this ARG (gene copies/ng of DNA) in the seed bank DNA increased 234 from 1961 to 1975 (Figure 1). In the case of sul1, a steady increase of this ARG abundance was 235 observed after 1970 (Supplementary Figure 1). The relative abundance of sul1 in seed bank 236 DNA increased from the same period, followed by a decline and a more recent increase after the 237 year ca. 2000 (Figure 1). The specific timeframe in which enrichment in ARG counts per ng of 238 DNA was observed concerned mainly the seed bank DNA, as opposed to the total bacterial 239 community. In addition, we could detect ARGs using a lower initial concentration of DNA for 240 the seed bank community (2 ng of DNA) compared to the total community (10-15 ng of DNA).

241 This further suggests a preferential enrichment of ARGs in seed bank bacteria compared to the 242 overall environmental background.

244 Characterization of the seed bank communities

245 Previous studies in Lake Geneva have shown a dramatic effect of human activity on the 246 nutritional status of the lake. The lake became eutrophic between 1954 and 1986, and this 247 modified the proportion of some members of the bacterial community in sediments (Wunderlin 248 et al. 2014a). Eutrophication is partly related to the same human activities that also shaped the 249 antibiotic era (for example, increased agricultural and livestock output and population pressure).

250 Since changes in microbial community composition as well as the spread of ARG within 251 populations can influence the record of antibiotic resistance, it was important to analyze seed 
252 bank community composition alongside ARG quantification. Representatives of six major

253 bacterial phyla (Proteobacteria, Firmicutes, Actinobacteria, Planctomycetes, Chlamydiae, and

254 Chloroflexi) were the main components of the bacterial seed bank community in sediments

255 (Supplementary Figure 2; Figure 2A). The overall community analysis revealed similarities in

256 the community composition in samples with higher relative abundance of either tet(W) or sul 1

257 (Figure 2B). For the former, a significant contribution of OTUs belonging to the Phylum

258 Firmicutes was observed, while in the case of sul1 no particular bacterial group was correlated

259 with increased accumulation.

260 In order to understand more clearly the relationship between ARG enrichment and seed bank

261 bacterial community, we next studied if the relative abundance of certain OTUs was correlated

262 with ARG levels. For this, we calculated the correlation coefficient between the relative

263 abundance of each OTU and the ARG relative abundance at different depths. Correlation

264 coefficients were plotted as a continuum to analyze the overall response of the community

265 (Figure 3A). In the case of tet $(\mathrm{W})$ most of the non-Firmicutes seed bank community was not

266 correlated with increased ARG relative abundance over time (most correlation coefficients were

267 close to 0; Figure 3A; dashed line). However, when the analysis is made only for representatives

268 of the Phylum Firmicutes, the distribution shifted significantly towards positive correlations

269 (comparison of the distribution for the total and Firmicutes communities; $t=16.52$, $\mathrm{df}=6171.6$,

$270 p$-value $<2.2 \mathrm{e}-16$; Figure $3 \mathrm{~A}$; solid line). This analysis confirmed the results of the total

271 community analysis (Figure 2B). We investigated further the ten most positively correlated

272 OTUs. Nine out of the ten operational taxonomic units (OTUs) positively correlated with tet(W)

273 relative abundance belong to Firmicutes (Table 1). The origin and ecology of bacteria related to

274 those OTUs suggests an equal contribution of bacteria from an environmental origin, mainly 
275 cellulose-degrading anaerobic bacteria such as Anaerobacterium (Horino et al. 2014)

276 (OTU00093 and OTU00528), Clostridium (Hernandez-Eugenio et al. 2002; Miller et al. 2011;

277 Zhilina et al. 2005) (OTU00262, OTU00084, and OTU02280), and Acetivibrio (Patel et al. 1980)

278 (OTU00908); and from human (or animal) intestinal origin such as Ruminoccous (Cann et al.

279 2016; Chassard et al. 2012; Crost et al. 2016) (OTU01612 and OTU01577). The OTUs

280 positively correlated to $\operatorname{tet}(\mathrm{W})$ represented a minor fraction of the bacterial seed bank community

281 even for those samples with the highest ARG abundance (relative OTU abundance not higher

282 than 5\%; Figure 3B).

283 The same analysis performed on sul1 showed a larger fraction of the community positively

284 correlated to relative ARG abundance (Figure $3 \mathrm{~A}$ ), but in contrast to $\operatorname{tet}(\mathrm{W})$ this is not

285 specifically significant for Firmicutes only. Instead, the 10 most positively correlated OTUs

286 belonged to diverse phylogenetic groups (Actinobacteria, Chloroflexi, Firmicutes, Proteobacteria,

287 Verrucomicrobia, and Planctomycetes) (Table 1). OTUs correlated positively with sul 1

288 abundance represented only minor fractions of the seed bank community (Figure 3A).

289 Interestingly, the correlation coefficients are higher for $\operatorname{tet}(\mathrm{W})$ than for sull, suggesting a 290 stronger relationship of particular OTUs with the former.

291 Even though the analysis of the total community suggests that the effect of increased relative

292 abundance of ARG appears to be independent from the generalized effect of eutrophication, we 293 performed the same correlation analysis between relative OTU abundance and the 294 iron/manganese ratio in sediments. The ratio of iron and manganese can be used as a proxy for 295 redox conditions in the water column (Corella et al. 2012; Koinig et al. 2003) and changes in the 296 relative concentration of these two elements have been shown to correlate with eutrophication in 297 Lake Geneva (Wunderlin et al. 2014a). Eutrophication in Lake Geneva is one of the 
298 environmental disturbances with the best ecological record. Long-term trends show a steady

299 increase of total phosphorus since 1957 with a peak in 1979. These values, together with

300 phosphate data since 1970, indicate a shift in trophic status of the lake from oligotrophic to

301 eutrophic taking place in the late 1960s. The system has since recovered, even though total

302 phosphorus levels are still double the values before 1960 (Lazzarotto \& Klein 2012). The results

303 show no overlap between the overall effect of eutrophication in specific OTUs (Supplementary

304 Figure 3) and the effect of ARG abundance in terms of the most correlated OTUs (Figures 3).

305

306 Discussion

307 Lake Geneva is one of the largest lakes in Europe and constitutes a major reservoir of drinking 308 water. The composition of bacterial communities (Haller et al. 2011; Sauvain et al. 2014), as 309 well as the presence of toxic metals (Pote et al. 2008), micropollutants (Bonvin et al. 2011), and 310 ARGs (Czekalski et al. 2012; Czekalski et al. 2014; Devarajan et al. 2015), has been monitored 311 regularly in its water column and sediments. All these studies have demonstrated the role of 312 human activity in the transfer of contaminants (including antibiotics) into sediments. Because of 313 these preliminary studies, Lake Geneva is an ideal model system to validate the use of the seed 314 bank bacterial community as a proxy to the effect of the historical use of antibiotics on the 315 abundance of ARGs in the environment. Our results show that studying the bacterial seed bank 316 community in sediments of Lake Geneva shows the historical increase in ARG abundance. There 317 was a clear link between seed bank taxonomy and accumulation of tet(W). This taxonomy318 specific effect has been well documented in the case of tetracycline (Roberts \& Schwarz 2016). 319 Tetracycline is a class of broad-spectrum antibiotics active against a wide range of bacteria, 320 including some atypical pathogens such as Mycoplasma and Chlamydia, and even eukaryotic 
321 parasites. In the USA, tetracycline became extensively used in production of livestock between

322 1950s and 1970s and remains today the second most commonly used antibiotic in agriculture

323 (Roberts \& Schwarz 2016). The situation in Switzerland is similar, according to a recent report

324 from the Swiss Federal Office of Public Health indicating that tetracycline (together with

325 penicillin) is the second most sold antibiotic product, after sulfonamides (FOPH 2016). In

326 Switzerland, the current use of tetracycline is mainly restricted to non-medical applications, with

327 a reported consumption below 1\% in hospitals (according to data covering the period from 2004

328 to 2015) and close to $11 \%$ in outpatient settings (FOPH 2016). In Switzerland the principal

329 medical use of tetracycline was reported for the period of 1955 to 1970 (Supplementary Table 1),

330 but has since reduced dramatically following the use of amoxicillin-clavulanate for skin and soft-

331 tissue infections and the increased use of cotromixazole (a combination of sulfonamides and

332 trimethoprim) for uncomplicated urinary tract infections, which represent the two most common

333 bacterial infections encountered in outpatient clinics and private medical practice.

334 Tetracycline binds to the elongating ribosome, affecting translation, and therefore resistance can

335 be acquired through diverse mechanisms (Davies \& Davies 2010; Roberts \& Schwarz 2016).

$336 \operatorname{tet}(\mathrm{W})$ is one of a series of ARGs conferring resistance through ribosomal protection and

337 although the ancestral source of the gene is unknown, it has been reported in both Gram-positive

338 and Gram-negative bacteria (Roberts \& Schwarz 2016). Our analysis suggest that medical

339 historical use (1995-1970) fits well with the observed peak of relative accumulation of tet(W) in

340 the seed bank DNA, which was highly correlated with changes in the abundance of Firmicutes.

341 One potential explanation for the link between medical use of tetracycline and tet(W) in

342 Fimicutes is the fact that the human gut microbiome can serve as a reservoir of ARGs, and in

343 particular to genes conferring resistance to tetracycline (de Vries et al. 2011; van Schaik 2015). 
344 A recent analysis of the human gut microbiome suggests that Firmicutes are highly prevalent

345 (Browne et al. 2016; Dethlefsen et al. 2007). More importantly, a recent study suggests that

346 sporulation is a widespread characteristic of the human microbiome (Browne et al. 2016), and it

347 is precisely these dormant forms that can contribute to the seed bank in human-impacted

348 ecosystems. However, linking tet(W) abundance and the human microbiome must not be seen as

349 a confirmation of the relationship between medical antibiotic use and increase of ARGs levels in

350 the environment. For example, a recent study monitoring the effect of tetracycline on the

351 performance of anaerobic digestors used in wastewater treatment has also shown a highly

352 significant increase in the relative abundance of spore-forming Firmicutes after treatment with a

353 concentration of $20 \mathrm{mg} / \mathrm{L}$ of tetracycline (Xiong et al. 2017). Overall the data suggest that

354 antibiotics such as tetracycline might select for specific groups of Firmicutes that can be later

355 found in the seed bank archives.

356 The same analysis performed on sulfonamides, another class of antibiotics with an industrial 357 history, shows a different trend. Sulfonamide drugs were also among the earliest antibiotics

358 discovered. The legacy of mass production of sulfonamide is reflected in one of the most broadly

359 disseminated case of drug resistance, both in terms of prevalence and taxonomy (Aminov 2010).

360 Resistance to this class of antibiotic is almost universally associated to genetic mobile elements

361 that confer a fitness advantage to the receptor bacteria as shown in the case of non-pathogenic

362 Escherichia coli (Enne et al. 2004). The abundance of sull may thus be indicative of a

363 dissemination trend of certain widespread mobile genetic elements (e.g. class-1 integrons)

364 (Gillings 2014; Skold 1976; Skold 2000) that may well carry other resistance elements.

365 Horizontal gene transfer mediated by mobile genetic elements is considered a major pathway of

366 ARG dissemination (Bengtsson-Palme et al. 2017; Berglund 2015). This particular mechanism 
367 of ARG dissemination overcomes taxonomic barriers, probably explaining the wide taxonomic

368 spectrum of bacterial seed bank groups correlated to sul1 quantification in the sediments.

369 The quantification of sul 1 in the sedimentary record in the 1970s matches early prescription

370 history of this antibiotic class (Supplementary Table 1). More recent detection could be

371 correlated to changes in guidelines to reduce usage of penicillin derivatives (such as co-

372 amoxicillin) for uncomplicated urinary tract infection in favor of cotrimoxazole

373 (Sulfamethoxazol-Trimethoprim combination), which may partially explain the common

374 occurrence of sul1 resistance gene in the seed bank DNA especially after 2005 (Supplementary

375 Table 1). At this time medical guidelines changed given the high rate of resistance of E. coli

376 (90\% of the etiology of cystitis in healthy adult female humans) to penicillin derivatives, leading

377 to the reintroduction of sulfonamides. Indeed, the resistance rate of $E$. coli to amoxicillin and to

378 amoxicillin-clavulanate respectively reached $52 \%$ and $23 \%$ of the isolates tested at the Lausanne

379 University Hospital Diagnostic Laboratory in 2016 (4581 strains), which has prompted clinicians

380 to use sulfonamides instead.

381

\section{Conclusions}

383 Previous studies of the historical legacy of the antibiotic era have come to contradictory 384 conclusions. On the one hand, they show the recent effect of human activity on ARGs in the 385 environment (Graham et al. 2016; Knapp et al. 2010; Thevenon et al. 2012), and suggest that 386 reducing non-therapeutic antibiotic use may reduce some of the environmental ARG legacy. On 387 the other hand, the results show that this is not universally applicable to all antibiotic classes and 388 that policies intended to reduce non-therapeutic use can have undesirable consequences (Graham 389 et al. 2016). Results for the accumulation of beta-lactamase genes in soils suggest that 
390 accumulation in soil reflected a broader expansion of antibiotic use across society, implying that

391 development of resistance in clinical and agricultural systems is mutually influential (Graham et

392 al. 2016). Our results generate valuable information for the debate regarding the long-term effect

393 of the antibiotic era as we show that antibiotics also affect a fraction of the microbial community

394 that will certainly outlast many of these policies: the seed bank bacterial community. This opens

395 up a new debate, concerning the potential long-term effect of these dormant and persistent

396 cellular structures and their potential for further spreading of ARGs in the environment.

397 Importantly however, we here by provide a proof of concept for a new way to study the historical

398 development of resistance that is applicable to many geographic regions and resistance

399 determinants and that does not rely on human archiving of environmental samples.

400

401 References

402

403

404

405

406

407

408

409

410

411

412

413

414

415

416

417

418

419

420

421

422

Abecasis AB, Serrano M, Alves R, Quintais L, Pereira-Leal JB, and Henriques AO. 2013. A genomic signature and the identification of new sporulation genes. J Bacteriol 195:21012115. 10.1128/JB.02110-12

Aminov RI. 2009. The role of antibiotics and antibiotic resistance in nature. Environ Microbiol 11:2970-2988. 10.1111/j.1462-2920.2009.01972.x

Aminov RI. 2010. A brief history of the antibiotic era: lessons learned and challenges for the future. Front Microbiol 1:134. 10.3389/fmicb.2010.00134

Aminov RI, and Mackie RI. 2007. Evolution and ecology of antibiotic resistance genes. FEMS Microbiol Lett 271:147-161. 10.1111/j.1574-6968.2007.00757.x

Baquero F, Martinez JL, and Canton R. 2008. Antibiotics and antibiotic resistance in water environments. Curr Opin Biotechnol 19:260-265. 10.1016/j.copbio.2008.05.006

Bengtsson-Palme J, Kristiansson E, and Larsson DGJ. 2017. Environmental factors influencing the development and spread of antibiotic resistance. FEMS Microbiol Rev. 10.1093/femsre/fux053

Berglund B. 2015. Environmental dissemination of antibiotic resistance genes and correlation to anthropogenic contamination with antibiotics. Infect Ecol Epidemiol 5:28564. 10.3402/iee.v5.28564

Bhullar K, Waglechner N, Pawlowski A, Koteva K, Banks ED, Johnston MD, Barton HA, and Wright GD. 2012. Antibiotic Resistance Is Prevalent in an Isolated Cave Microbiome. PLOS ONE 7. ARTN e34953 
423

424

425

426

427

428

429

430

431

432

433

434

435

436

437

438

439

440

441

442

443

444

445

446

447

448

449

450

451

452

453

454

455

456

457

458

459

460

461

462

463

464

465

466

467

10.1371/journal.pone.0034953

Blair JM, Webber MA, Baylay AJ, Ogbolu DO, and Piddock LJ. 2015. Molecular mechanisms of antibiotic resistance. Nat Rev Microbiol 13:42-51. 10.1038/nrmicro3380

Bonvin F, Rutler R, Chevre N, Halder J, and Kohn T. 2011. Spatial and Temporal Presence of a Wastewater-Derived Micropollutant Plume in Lake Geneva. Environmental Science \& Technology 45:4702-4709. 10.1021/es2003588

Browne HP, Forster SC, Anonye BO, Kumar N, Neville BA, Stares MD, Goulding D, and Lawley TD. 2016. Culturing of 'unculturable' human microbiota reveals novel taxa and extensive sporulation. Nature 533:543-546. 10.1038/nature17645

Cann I, Bernardi RC, and Mackie RI. 2016. Cellulose degradation in the human gut: Ruminococcus champanellensis expands the cellulosome paradigm. Environ Microbiol 18:307-310. 10.1111/1462-2920.13152

Carlet J, Collignon P, Goldmann D, Goossens H, Gyssens IC, Harbarth S, Jarlier V, Levy SB, N'Doye B, Pittet D, Richtmann R, Seto WH, van der Meer JW, and Voss A. 2011. Society's failure to protect a precious resource: antibiotics. Lancet 378:369-371. 10.1016/S0140-6736(11)60401-7

Chassard C, Delmas E, Robert C, Lawson PA, and Bernalier-Donadille A. 2012. Ruminococcus champanellensis sp. nov., a cellulose-degrading bacterium from human gut microbiota. Int J Syst Evol Microbiol 62:138-143. 10.1099/ijs.0.027375-0

Corella JP, Brauer A, Mangili C, Rull V, Vegas-Vilarrubia T, Morellon M, and Valero-Garces BL. 2012. The 1.5-ka varved record of Lake Montcortes (southern Pyrenees, NE Spain). Quaternary Research 78:323-332. 10.1016/j.yqres.2012.06.002

Crost EH, Tailford LE, Monestier M, Swarbreck D, Henrissat B, Crossman LC, and Juge N. 2016. The mucin-degradation strategy of Ruminococcus gnavus: The importance of intramolecular trans-sialidases. Gut Microbes 7:302-312. 10.1080/19490976.2016.1186334

Czekalski N, Berthold T, Caucci S, Egli A, and Burgmann H. 2012. Increased levels of multiresistant bacteria and resistance genes after wastewater treatment and their dissemination into lake geneva, Switzerland. Front Microbiol 3:106. 10.3389/fmicb.2012.00106

Czekalski N, Gascon Diez E, and Burgmann H. 2014. Wastewater as a point source of antibioticresistance genes in the sediment of a freshwater lake. ISME J 8:1381-1390. 10.1038/ismej.2014.8

D'Costa VM, King CE, Kalan L, Morar M, Sung WWL, Schwarz C, Froese D, Zazula G, Calmels F, Debruyne R, Golding GB, Poinar HN, and Wright GD. 2011. Antibiotic resistance is ancient. Nature 477:457-461. 10.1038/nature10388

Davies J, and Davies D. 2010. Origins and evolution of antibiotic resistance. Microbiol Mol Biol Rev 74:417-433. 10.1128/MMBR.00016-10

de Vries LE, Vallès Y, Agersø Y, Vaishampayan PA, García-Montaner A, Kuehl JV, Christensen H, Barlow M, and Francino MP. 2011. The Gut as Reservoir of Antibiotic Resistance: Microbial Diversity of Tetracycline Resistance in Mother and Infant. PLOS ONE 6:e21644. 10.1371/journal.pone.0021644

Dethlefsen L, McFall-Ngai M, and Relman DA. 2007. An ecological and evolutionary perspective on human-microbe mutualism and disease. Nature 449:811-818. 10.1038 /nature 06245

Peer] reviewing PDF | (2017:10:21258:1:0:NEW 24 Nov 2017) 
468 Devarajan N, Laffite A, Graham ND, Meijer M, Prabakar K, Mubedi JI, Elongo V, Mpiana PT,

469

470

471

472

473

474

475

476

477

478

479

480

481

482

483

484

485

486

487

488

489

490

491

492

493

494

495

496

497

498

499

500

501

502

503

504

505

506

507

508

509

510

511

512

513

Ibelings BW, Wildi W, and Pote J. 2015. Accumulation of clinically relevant antibioticresistance genes, bacterial load, and metals in freshwater lake sediments in Central Europe. Environ Sci Technol 49:6528-6537. 10.1021/acs.est.5b01031

Driks A. 2002. Overview: Development in bacteria: spore formation in Bacillus subtilis. Cell Mol Life Sci 59:389-391.

Enne VI, Bennett PM, Livermore DM, and Hall LM. 2004. Enhancement of host fitness by the sul2-coding plasmid p9123 in the absence of selective pressure. J Antimicrob Chemother 53:958-963. 10.1093/jac/dkh217

FOPH. 2016. Swiss Antibiotic Resistance Report 2016. Usage of Antibiotics and Occurrence of Antibiotic Resistance in Bacteria from Humans and Animals in Switzerland. In: Heim HACD, editor: Federal Office of Public Health. p 176.

Gillings MR. 2014. Integrons: past, present, and future. Microbiol Mol Biol Rev 78:257-277. 10.1128/MMBR.00056-13

Goh EB, Yim G, Tsui W, McClure J, Surette MG, and Davies J. 2002. Transcriptional modulation of bacterial gene expression by subinhibitory concentrations of antibiotics. Proc Natl Acad Sci U S A 99:17025-17030. 10.1073/pnas.252607699

Graham DW, Knapp CW, Christensen BT, McCluskey S, and Dolfing J. 2016. Appearance of $\beta$-lactam Resistance Genes in Agricultural Soils and Clinical Isolates over the 20th Century. Scientific Reports 6:21550. 10.1038/srep21550

https://www.nature.com/articles/srep21550\#supplementary-information

Haller L, Tonolla M, Zopfi J, Peduzzi R, Wildi W, and Pote J. 2011. Composition of bacterial and archaeal communities in freshwater sediments with different contamination levels (Lake Geneva, Switzerland). Water Res 45:1213-1228. 10.1016/j.watres.2010.11.018

Herlemann DP, Labrenz M, Jurgens K, Bertilsson S, Waniek JJ, and Andersson AF. 2011. Transitions in bacterial communities along the $2000 \mathrm{~km}$ salinity gradient of the Baltic Sea. ISME J 5:1571-1579. 10.1038/ismej.2011.41

Hernandez-Eugenio G, Fardeau ML, Cayol JL, Patel BK, Thomas P, Macarie H, Garcia JL, and Ollivier B. 2002. Clostridium thiosulfatireducens sp. nov., a proteolytic, thiosulfate- and sulfur-reducing bacterium isolated from an upflow anaerobic sludge blanket (UASB) reactor. Int J Syst Evol Microbiol 52:1461-1468. 10.1099/00207713-52-5-1461

Heuer H, and Smalla K. 2007. Manure and sulfadiazine synergistically increased bacterial antibiotic resistance in soil over at least two months. Environ Microbiol 9:657-666. 10.1111/j.1462-2920.2006.01185.x

Horino H, Fujita T, and Tonouchi A. 2014. Description of Anaerobacterium chartisolvens gen. nov., sp. nov., an obligately anaerobic bacterium from Clostridium rRNA cluster III isolated from soil of a Japanese rice field, and reclassification of Bacteroides cellulosolvens Murray et al. 1984 as Pseudobacteroides cellulosolvens gen. nov., comb. nov. Int J Syst Evol Microbiol 64:1296-1303. 10.1099/ijs.0.059378-0

Knapp CW, Dolfing J, Ehlert PAI, and Graham DW. 2010. Evidence of Increasing Antibiotic Resistance Gene Abundances in Archived Soils since 1940. Environmental Science \& Technology 44:580-587. 10.1021/es901221x

Koinig KA, Shotyk W, Lotter AF, Ohlendorf C, and Sturm M. 2003. 9000 years of geochemical evolution of lithogenic major and trace elements in the sediment of an alpine lake - the role of climate, vegetation, and land-use history. Journal of Paleolimnology 30:307-320. Doi 10.1023/A:1026080712312

Peer] reviewing PDF | (2017:10:21258:1:0:NEW 24 Nov 2017) 
514 Kozich JJ, Westcott SL, Baxter NT, Highlander SK, and Schloss PD. 2013. Development of a

515

516

517

518

519

520

521

522

523

524

525

526

527

528

529

530

531

532

533

534

535

536

537

538

539

540

541

542

543

544

545

546

547

548

549

550

551

552

553

554

555

556

557

558 dual-index sequencing strategy and curation pipeline for analyzing amplicon sequence data on the MiSeq Illumina sequencing platform. Appl Environ Microbiol 79:5112-5120. 10.1128/AEM.01043-13

Kümmerer K. 2009. Antibiotics in the aquatic environment - A review - Part I. Chemosphere 75:417-434. https://doi.org/10.1016/j.chemosphere.2008.11.086

Lazzarotto J, and Klein A. 2012. Physical-chemical changes in the waters of Lake Geneva (major elements). In: 2011 RdlCIplPdEdLclPC, editor. Lausanne, Switzerland.

Lee ZM, Bussema C, 3rd, and Schmidt TM. 2009. rrnDB: documenting the number of rRNA and tRNA genes in bacteria and archaea. Nucleic Acids Res 37:D489-493. $10.1093 / \mathrm{nar} / \mathrm{gkn} 689$

Lennon JT, and Jones SE. 2011. Microbial seed banks: the ecological and evolutionary implications of dormancy. Nat Rev Microbiol 9:119-130. 10.1038/nrmicro2504

Marti E, Variatza E, and Balcazar JL. 2014. The role of aquatic ecosystems as reservoirs of antibiotic resistance. Trends Microbiol 22:36-41. 10.1016/j.tim.2013.11.001

Martinez JL. 2008. Antibiotics and antibiotic resistance genes in natural environments. Science 321:365-367. 10.1126/science.1159483

McMurdie PJ, and Holmes S. 2013. phyloseq: an R package for reproducible interactive analysis and graphics of microbiome census data. PLOS ONE 8:e61217. 10.1371/journal.pone.0061217

Miller DA, Suen G, Bruce D, Copeland A, Cheng JF, Detter C, Goodwin LA, Han CS, Hauser LJ, Land ML, Lapidus A, Lucas S, Meincke L, Pitluck S, Tapia R, Teshima H, Woyke T, Fox BG, Angert ER, and Currie CR. 2011. Complete genome sequence of the cellulosedegrading bacterium Cellulosilyticum lentocellum. J Bacteriol 193:2357-2358. 10.1128/JB.00239-11

Oksanen J, Blanchet FG, Friendly M, Kindt R, Legendre P, McGlinn D, Minchin PR, O'Hara RB, Simpson GL, Solymos P, Henry M, Stevens H, Szoecs E, and Wagner H. 2017. vegan: Community Ecology Package. R package version 2.4-3. Available at https://CRAN.Rproject.org/package=vegan.

Patel GB, Khan AW, Agnew BJ, and Colvin JR. 1980. Isolation and Characterization of an Anaerobic, Cellulolytic Microorganism, Acetivibrio cellulolyticus gen. nov., sp. nov. $\dagger$. International Journal of Systematic and Evolutionary Microbiology 30:179-185. doi:10.1099/00207713-30-1-179

Pote J, Haller L, Loizeau JL, Garcia Bravo A, Sastre V, and Wildi W. 2008. Effects of a sewage treatment plant outlet pipe extension on the distribution of contaminants in the sediments of the Bay of Vidy, Lake Geneva, Switzerland. Bioresour Technol 99:7122-7131. 10.1016/j.biortech.2007.12.075

Quast C, Pruesse E, Yilmaz P, Gerken J, Schweer T, Yarza P, Peplies J, and Glockner FO. 2013. The SILVA ribosomal RNA gene database project: improved data processing and webbased tools. Nucleic Acids Res 41:D590-596. 10.1093/nar/gks1219

Roberts MC, and Schwarz S. 2016. Tetracycline and Phenicol Resistance Genes and Mechanisms: Importance for Agriculture, the Environment, and Humans. J Environ Qual 45:576-592. 10.2134/jeq2015.04.0207

Sauvain L, Bueche M, Junier T, Masson M, Wunderlin T, Kohler-Milleret R, Diez EG, Loizeau JL, Tercier-Waeber ML, and Junier P. 2014. Bacterial communities in trace metal 
559

560

561

562

563

564

565

566

567

568

569

570

571

572

573

574

575

576

577

578

579

580

581

582

583

584

585

586

587

588

589

590

591

592

593

594

595

596

597

598

599

600

601

602

603

604

contaminated lake sediments are dominated by endospore-forming bacteria. Aquatic Sciences 76:S33-S46. 10.1007/s00027-013-0313-8

Schloss PD, Westcott SL, Ryabin T, Hall JR, Hartmann M, Hollister EB, Lesniewski RA, Oakley BB, Parks DH, Robinson CJ, Sahl JW, Stres B, Thallinger GG, Van Horn DJ, and Weber CF. 2009. Introducing mothur: open-source, platform-independent, communitysupported software for describing and comparing microbial communities. Appl Environ Microbiol 75:7537-7541. 10.1128/AEM.01541-09

Skold O. 1976. R-factor-mediated resistance to sulfonamides by a plasmid-borne, drug-resistant dihydropteroate synthase. Antimicrob Agents Chemother 9:49-54.

Skold O. 2000. Sulfonamide resistance: mechanisms and trends. Drug Resist Updat 3:155-160. 10.1054/drup.2000.0146

Taylor NG, Verner-Jeffreys DW, and Baker-Austin C. 2011. Aquatic systems: maintaining, mixing and mobilising antimicrobial resistance? Trends Ecol Evol 26:278-284. 10.1016/j.tree.2011.03.004

Team RC. 2014. R: A Language and Environment for Statistical Computing.

Thevenon F, Adatte T, Wildi W, and Pote J. 2012. Antibiotic resistant bacteria/genes dissemination in lacustrine sediments highly increased following cultural eutrophication of Lake Geneva (Switzerland). Chemosphere 86:468-476. 10.1016/j.chemosphere.2011.09.048

van Schaik W. 2015. The human gut resistome. Philos Trans R Soc Lond B Biol Sci 370:20140087. 10.1098/rstb.2014.0087

Walsh F, Ingenfeld A, Zampicolli M, Hilber-Bodmer M, Frey JE, and Duffy B. 2011. Real-time PCR methods for quantitative monitoring of streptomycin and tetracycline resistance genes in agricultural ecosystems. J Microbiol Methods 86:150-155. 10.1016/j.mimet.2011.04.011

Wright GD. 2010. Antibiotic resistance in the environment: a link to the clinic? Curr Opin Microbiol 13:589-594. 10.1016/j.mib.2010.08.005

Wunderlin T, Corella J, Junier T, Bueche M, Loizeau J-L, Girardclos Sp, and Junier P. 2014a. Endospore-forming bacteria as new proxies to assess impact of eutrophication in Lake Geneva (Switzerland, ÄiFrance). Aquatic Sciences 76:103-116. 10.1007/s00027-0130329-0

Wunderlin T, Junier T, Paul C, Jeanneret N, and Junier P. 2016. Physical Isolation of Endospores from Environmental Samples by Targeted Lysis of Vegetative Cells. $J$ Vis Exp. $10.3791 / 53411$

Wunderlin T, Junier T, Roussel-Delif L, Jeanneret N, and Junier P. 2013. Stage 0 sporulation gene $\mathrm{A}$ as a molecular marker to study diversity of endospore-forming Firmicutes. Environ Microbiol Rep 5:911-924. 10.1111/1758-2229.12094

Wunderlin T, Junier T, Roussel-Delif L, Jeanneret N, and Junier P. 2014b. Endospore-enriched sequencing approach reveals unprecedented diversity of Firmicutes in sediments. Environ Microbiol Rep 6:631-639.

Xiong Y, Harb M, and Hong PY. 2017. Performance and microbial community variations of anaerobic digesters under increasing tetracycline concentrations. Appl Microbiol Biotechnol. 10.1007/s00253-017-8253-1

Zhilina TN, Kevbrin VV, Turova TP, Lysenko AM, Kostrikina NA, and Zavarzin GA. 2005. [Clostridium alkalicellum sp. nov., an obligately alkaliphilic cellulolytic bacterium from a soda lake in the Baikal region]. Mikrobiologiia 74:642-653. 


\section{Table $\mathbf{1}$ (on next page)}

Correlation analysis between individual OTUs and relative abundance of tet(W) and sul1.

Top 10 most positively and negatively correlated OTUs. For tet(W) gene, mostly OTUs belonging to Firmicutes have been correlated to tet(W) abundance. In contrast, for sul1, OTUs correlated to sul1 abundance belong to many phyla. 


\section{Tables}

2

3 Table 1. Correlation analysis between individual OTUs and relative abundance of tet( $\mathrm{W})$ and

4 sull. Top 10 most positively and negatively correlated OTUs.

5

\begin{tabular}{|l|l|l|l|l|}
\hline Gene & OTU & Phylum & Genus & Correlation coefficient \\
\hline tet(W) & Otu00093 & Firmicutes & Anaerobacterium & 0.7890 \\
\hline & Otu01612 & Firmicutes & Lachnoclostridium & 0.7391 \\
\hline & Otu00262 & Firmicutes & Clostridiaceae 1 unclassified & 0.7136 \\
\hline & Otu00528 & Firmicutes & Clostridium unclassified & 0.6990 \\
\hline & Otu01577 & Firmicutes & Ruminococcus 1 & 0.6791 \\
\hline & Otu00084 & Firmicutes & Ruminococcacea unclassified & 0.6722 \\
\hline & Otu00908 & Firmicutes & Ruminococcacea unclassified & 0.6684 \\
\hline & Otu02280 & Firmicutes & Epulopiscium & 0.6684 \\
\hline & Out01131 & Verrucomicrobia & Verrucomicrobiales unclassified & 0.6659 \\
\hline & Otu00529 & Firmicutes & Geobacillus & 0.6652 \\
\hline sul1 & Otu00318 & Actinobacteria & Mycobacterium & 0.6656 \\
\hline & Otu00382 & Chloroflexi & Caldilineaceae unclassified & 0.6517 \\
\hline & Otu00975 & Firmicutes & Ruminiclostridium 1 & 0.6479 \\
\hline & Otu03004 & Firmicutes & Symbiobacterium & 0.6341 \\
\hline & Otu03302 & Actinobacteria & Actinobacteria unclassified & 0.6195 \\
\hline & Otu00155 & Proteobacteria & Hypomicrobium & 0.6176 \\
\hline & Otu00604 & Verrucomicrobia & Verrucomicrobia unclassified & 0.6170 \\
\hline & Otu00853 & Acidobacteria & Subgroup 6 unclassified & 0.6103 \\
\hline & Otu02777 & Actinobacteria & Tessaracoccus & 0.6095 \\
\hline & Otu01652 & Planctoymcetes & Plactomycetaceae unclassified & 0.6092 \\
\hline & & & \\
\hline & & & \\
\hline & & & \\
\hline & &
\end{tabular}

6 


\section{Figure 1 (on next page)}

Tetracycline and Sulfonamide resistance in total bacterial community and in the seed bank over time.

Relative abundance (gene copies/ng of extracted DNA) of two genes conferring resistance to the antibiotics tetracycline (tet(W)) and sulfonamide (sul1) in sediment samples covering the period between 1920 and 2010 in Lake Geneva, Switzerland. Quantification was made in DNA extracted from the seed bank (SB DNA) and total microbial community (total DNA). 
PeerJ

$\operatorname{tet}(W)$

tet(W) copies / ng DNA

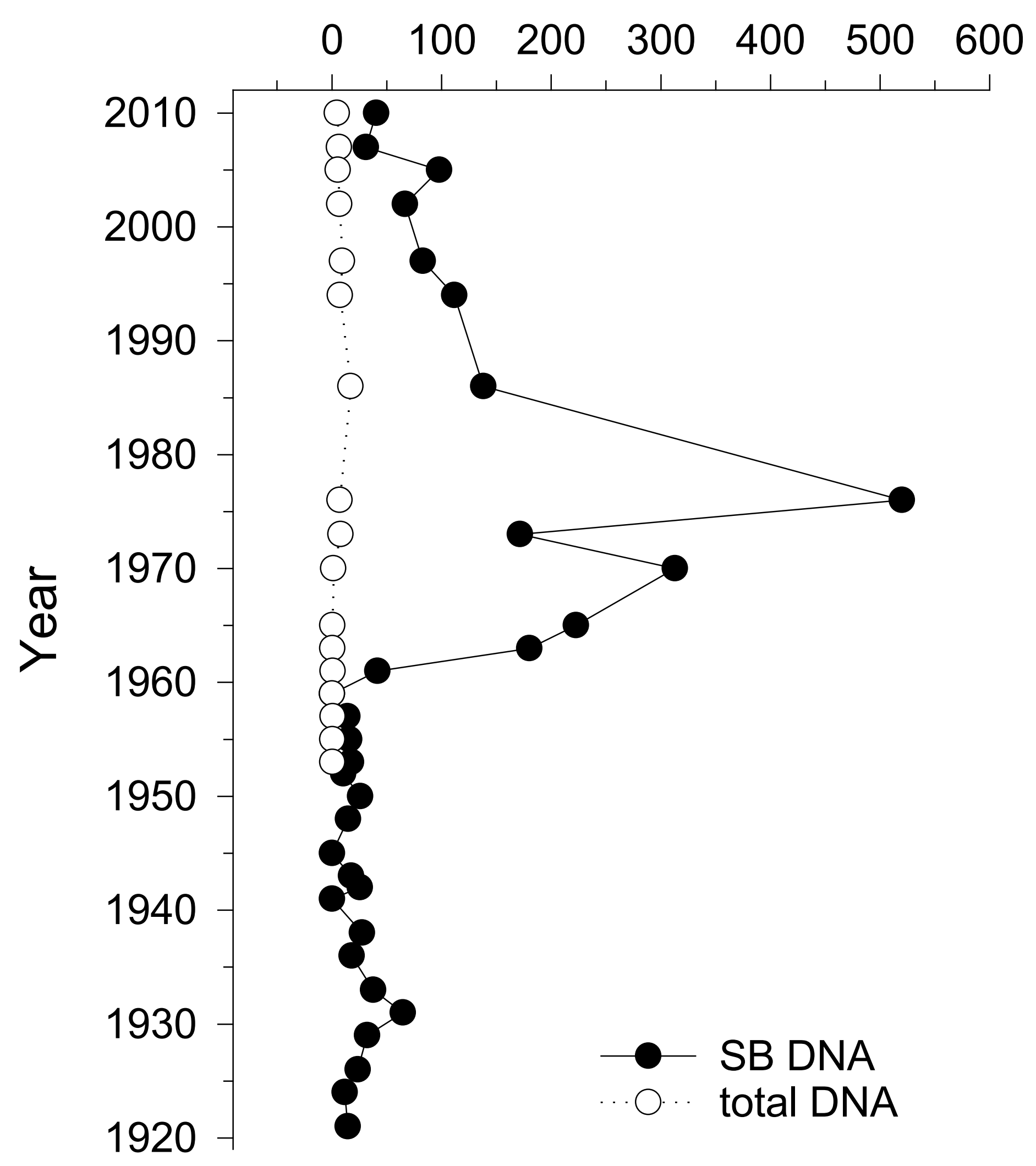

Manuscript to be reviewed

\section{sul1}

sul1 copies / ng DNA

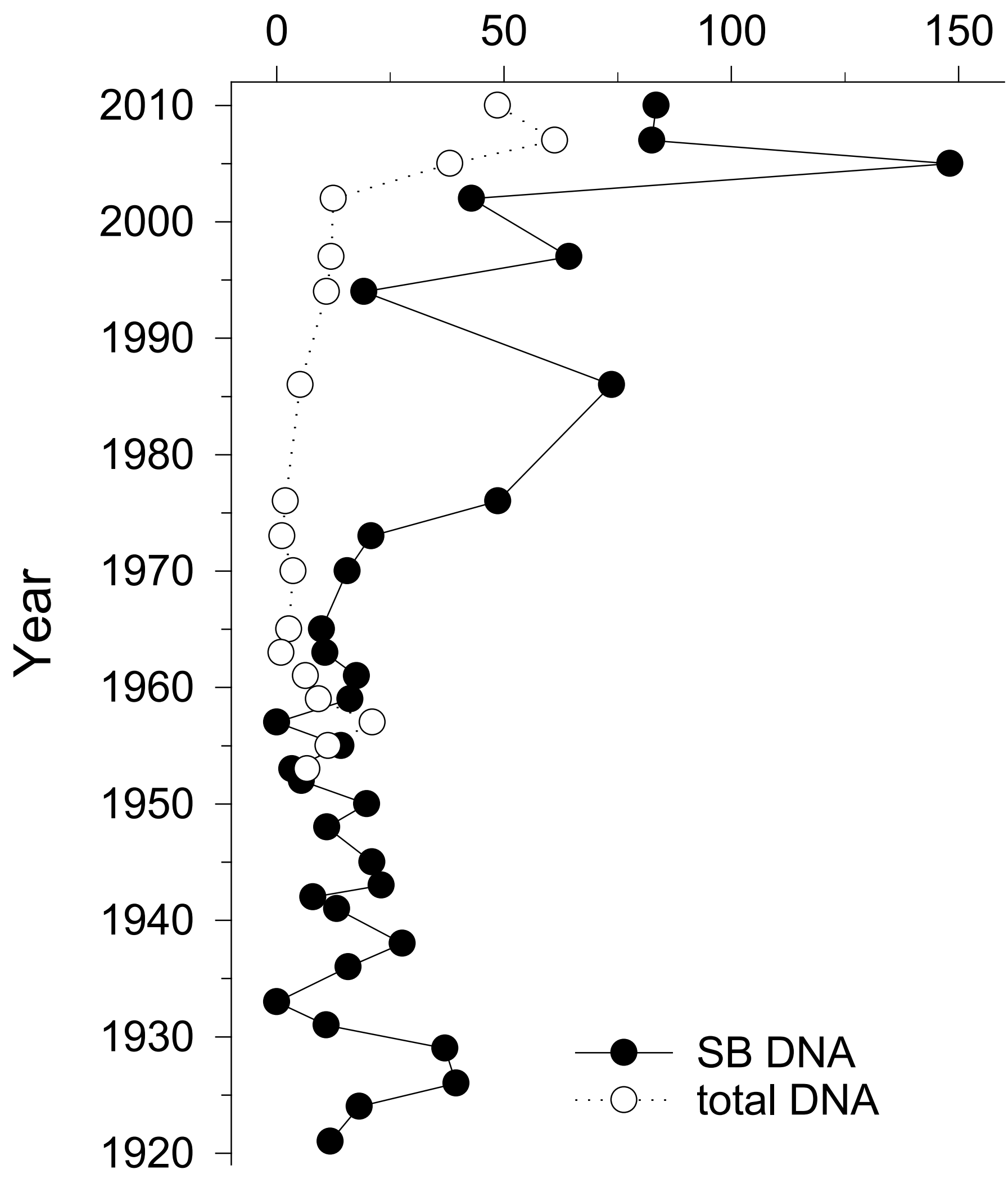


Figure 2 (on next page)

Seed bank community composition in sediments from Lake Geneva.

A. Contribution (relative abundance) of individual genera from the six most abundant bacterial phyla present in the sediment samples. B. Principal coordinates analysis (PCOA) of the seed bank bacterial community showing the effect of lake eutrophication (Axis 1; vector depth) and the accumulation of ARG (vector tet(W) and sul1). 
A.
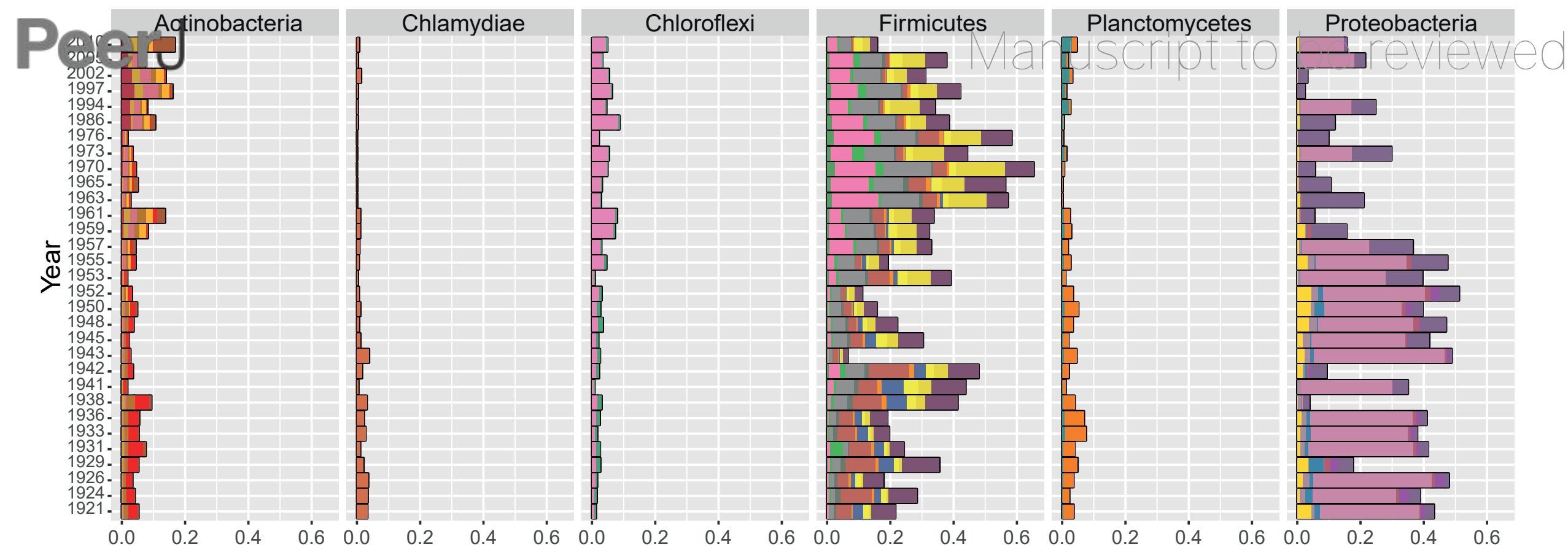

Genus

Anaeromyxobacter

Arenimonas

Arthrobacter

Bacillus

Chloroflexi_unclassified

Clostridium_sensu_stricto_1

Clostridium sensu stricto 13

Cryobacterium

D8A-2_unclassified

Fodinicola

Abundance

Gaiella

Gaiellales_unclassified

KD4-96_unclassified

Massilia

MB-A2-108_unclassified

Mesorhizobium

OPB54 unclassified

Paenibācillus

Paenisporosarcina

Parachlamydiaceae_unclassified
PeM15 unclassified

Peptostreptococcaceae_unclassified

Pir4_lineage

Planctomycetaceae unclassified

Polaromonas

Rhizobium

Ruminiclostridium 1

Ruminococcaceae_unclassified

Sideroxydans

Turicibacter

B.

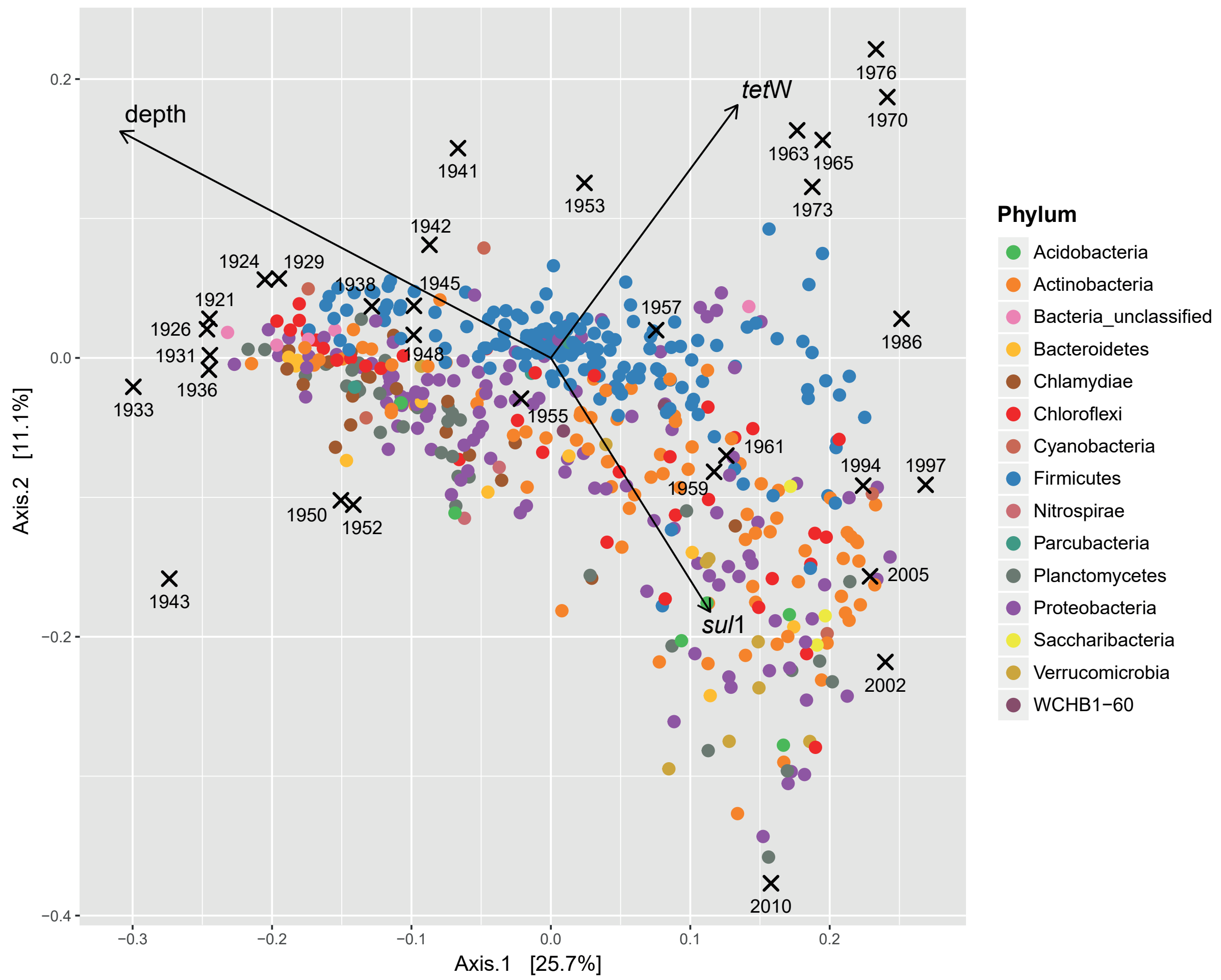


Figure 3 (on next page)

Correlation of specific OTUs to the relative abundance of ARGs in sediments.

A. Spearman correlation coefficients calculated for the relative abundance of each individual OTU and ARG frequency at different depths. The correlation coefficients were plotted as a continuum for the non-Firmicutes seed bank community (dashed line) or the OTUs belonging to Fimicutes only (solid line). B. Relative abundance of the ten most positively OTUs correlated with the relative abundance of each individual ARG. 
A. $\operatorname{tet}(\mathrm{W})$

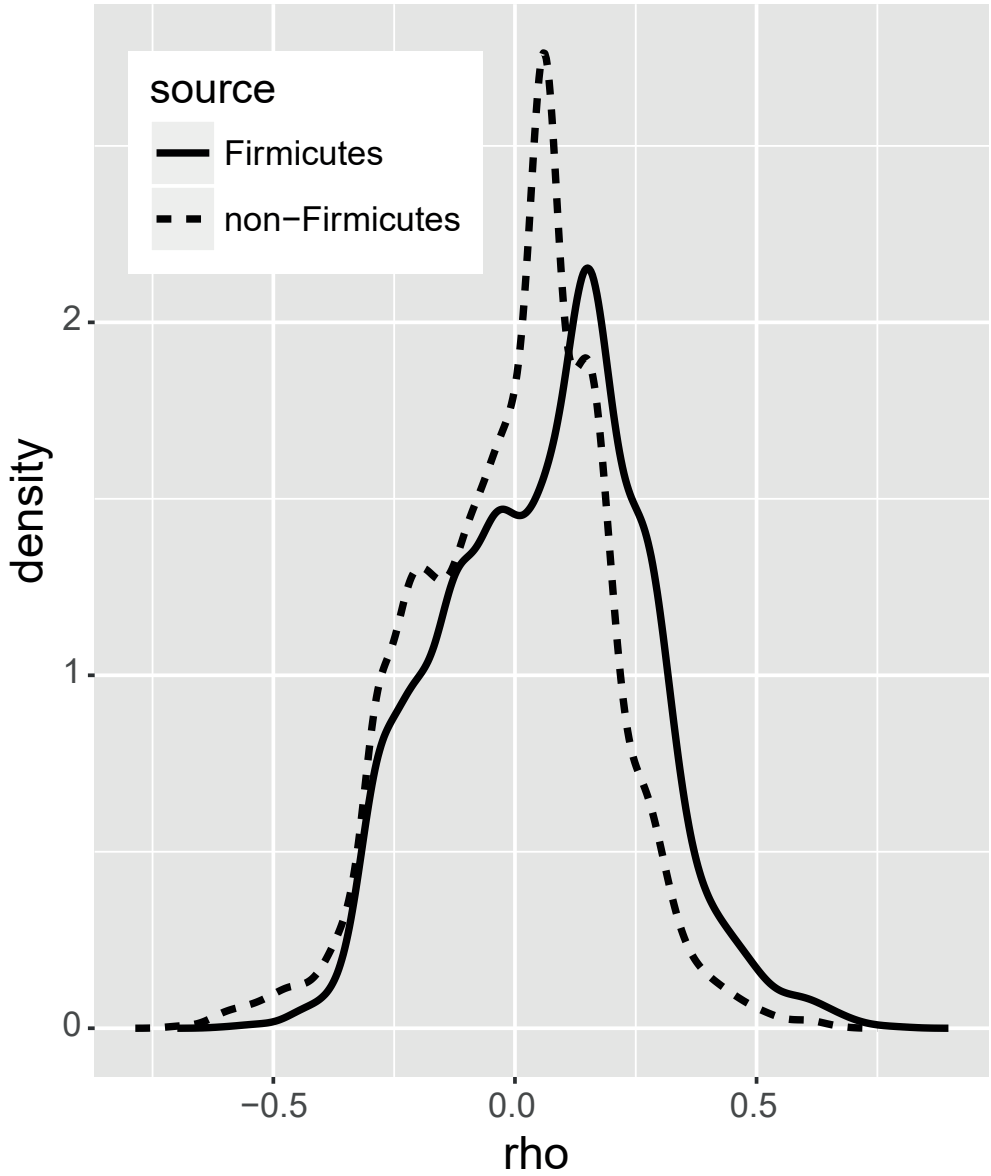

sul1

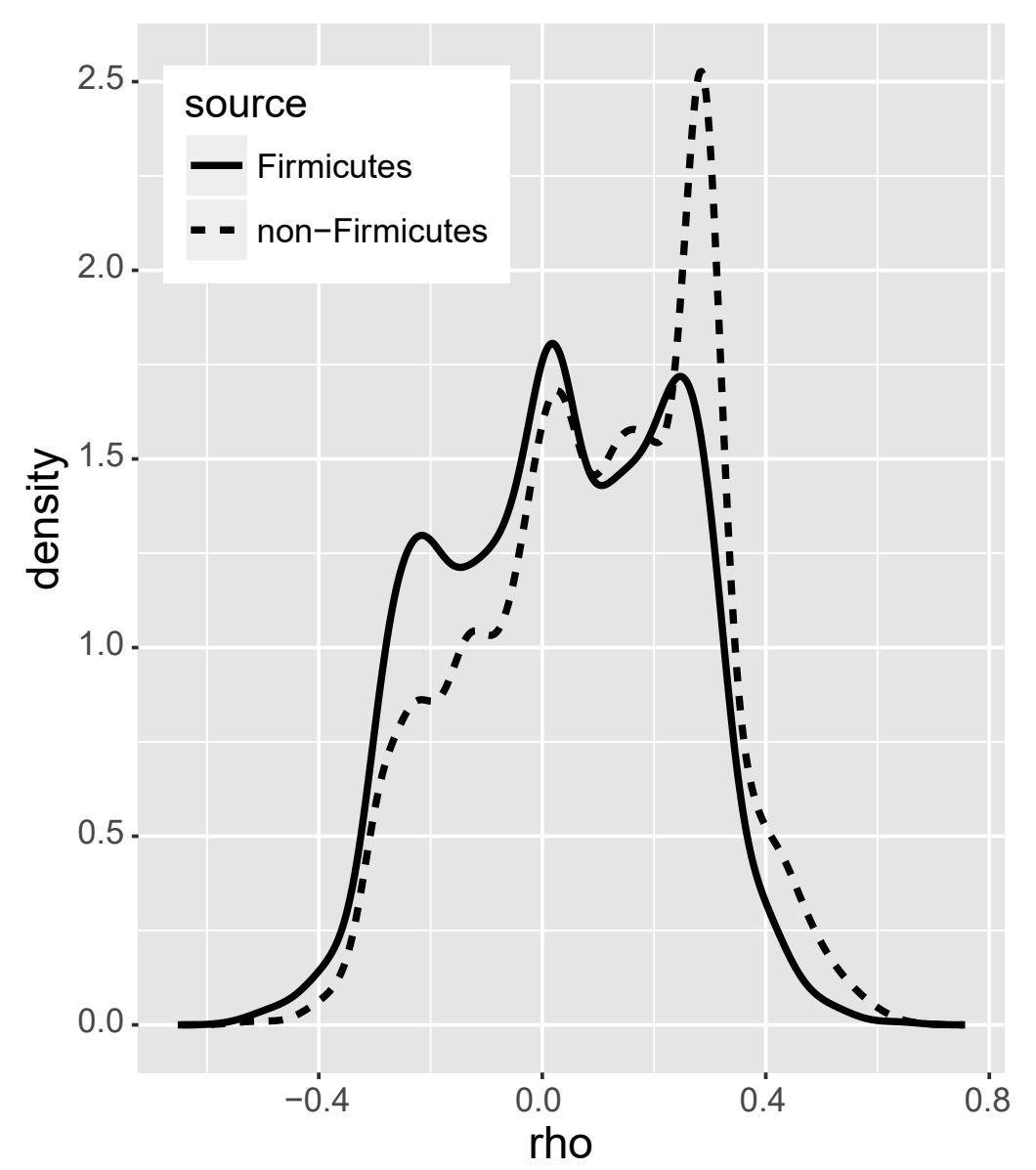

B. tet(W) - most correlated OTUs

Manuscript to be reviewed

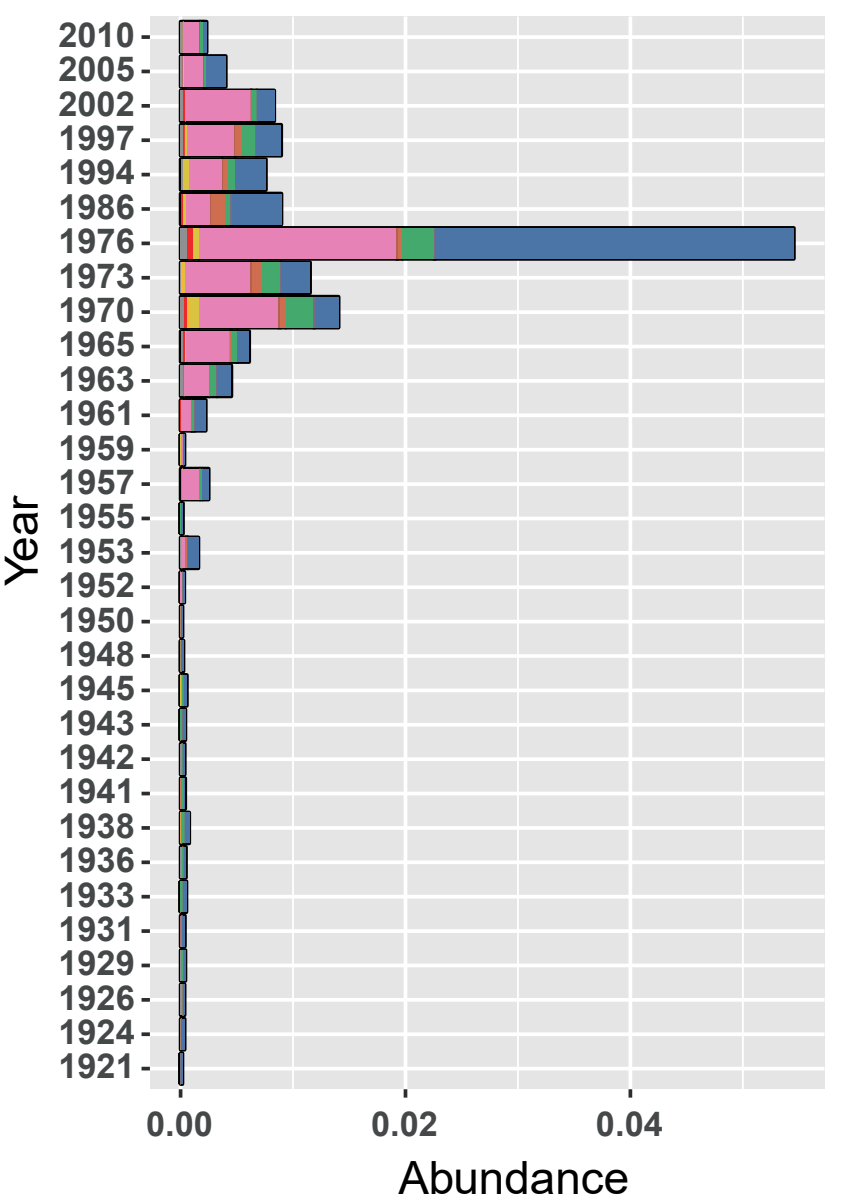

\section{OTU}

Otu00093;Anaerobacterium;Firmicutes

Otu01612; Lachnoclostridium;Firmicutes

Otu00262;Clostridiaceae_1_unclassified;Firmicutes

Otu00528;Clostridiales_unclassified;Firmicutes

Otu01577; Ruminococcus 1; Firmicutes

Otu00084;Ruminococcaceae_unclassified;Firmicutes

Otu00908;Ruminococcaceae unclassified;Firmicutes

Otu02280;Epulopiscium;Firmicutes

Otu01131;Verrucomicrobiales_unclassified;Verrucomicrobia

Otu00529;Geobacillus;Firmicutes

\section{sul1 - most correlated OTUs}

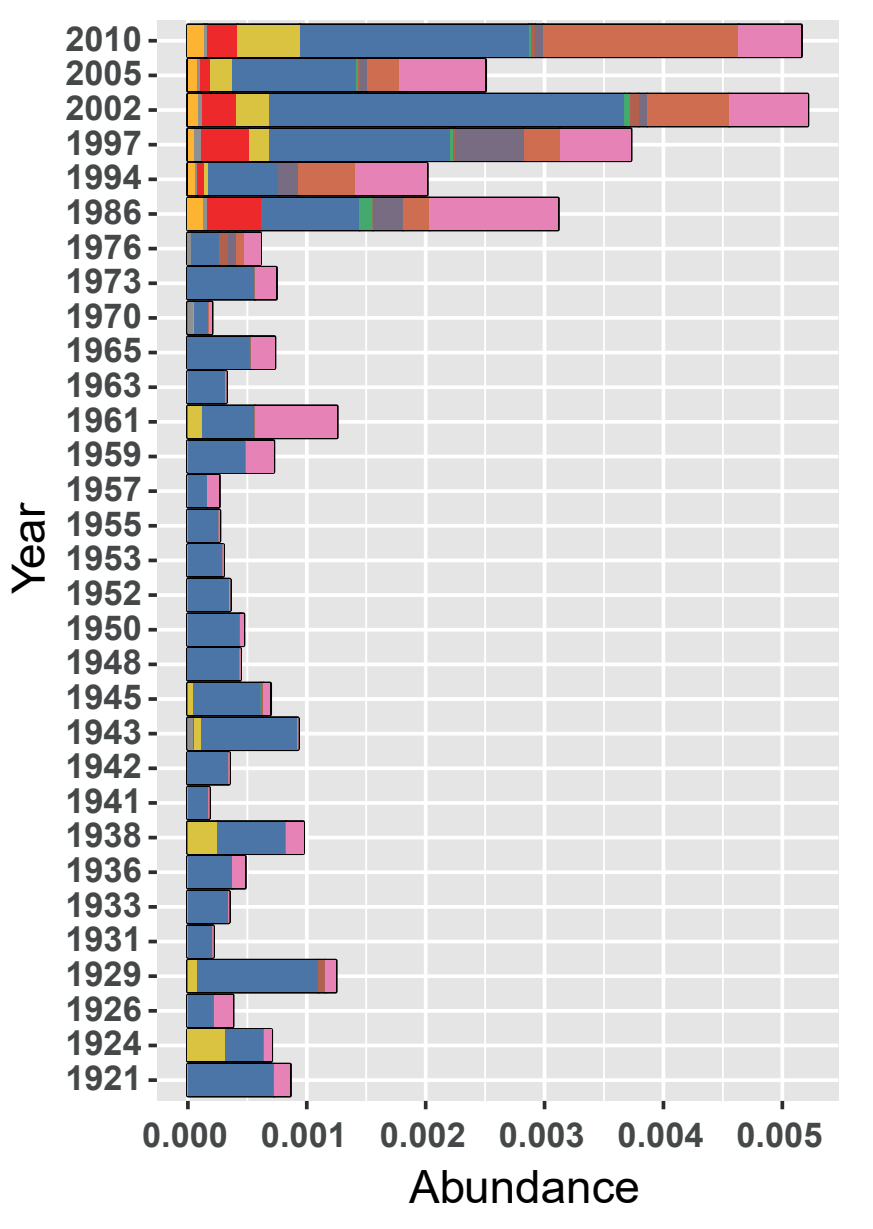

OTU

Otu00318;Mycobacterium;Actinobacteria

Otu00382;Caldilineaceae_unclassified;Chloroflexi

Otu00975;Ruminiclostridium_1;Firmicutes

Otu03004;Symbiobacterium;Firmicutes

Otu03302;Actinobacteria_unclassified;Actinobacteria

Otu00155;Hyphomicrobium;Proteobacteria

Otu00604;Verrucomicrobia_unclassified;Verrucomicrobia

Otu00853;Subgroup_6_unclassified;Acidobacteria

Otu02777; Tessaracoccus;Actinobacteria

Otu01652;Planctomycetaceae_unclassified;Planctomycetes 